\title{
A rare cause of rectal bleeding
}

\author{
Hsing-Hung Cheng ${ }^{1,2}$ (D), Tsung-Wei Chen ${ }^{1,3}$ (D), Jen-Wei Chou 1,2,4 (D) \\ 'School of Medicine, China Medical University, Taichung, Taiwan, Republic of China \\ 2Division of Gastroenterology and Hepatology, Department of Internal Medicine, China Medical University Hospital, Taichung, Taiwan, Republic \\ of China \\ ${ }^{3}$ Department of Pathology, China Medical University Hospital, Taichung, Taiwan, Republic of China \\ ${ }^{4}$ Taiwan Association for the Study of Small Intestinal Diseases, Taiwan, Republic of China
}

Cite this article as: Cheng HH, Chen TW, Chou JW. A rare cause of rectal bleeding. Turk J Gastroenterol 2019; 30(11): 984-5.

\section{QUESTION}

An 18-year-old male student was admitted to our hospital because of a 2-month history of intermittent bloody stools. Furthermore, he complained of left abdominal pain, tenesmus, and weight loss of $5 \mathrm{~kg}$. He had undergone a hemorrhoidectomy 2 years ago. He denied any relevant medical history. Moreover, he denied having the habit of smoking or alcohol consumption. On physical examination, mild tenderness without rebound tenderness was observed in his left abdomen. Digital rectal examination showed mild prolapse of the anus. Laboratory test results were unremarkable, except an albumin level of 3.1 g/dL (normal 3.8-4.5 g/dL) and a hemoglobin level of 10.9 g/dL (normal 13-15 g/dL). Colonoscopy was performed; it revealed circular tumor-like lesions in the distal rectum (Figure 1). Because the patient refused to undergo surgical resection of the rectal lesions, we planned endoscopic resection. We resected the rectal tumor-like lesions using snare polypectomy and sent them for pathological examination (Figure 2).

What is your diagnosis of these rectal tumor-like lesions?

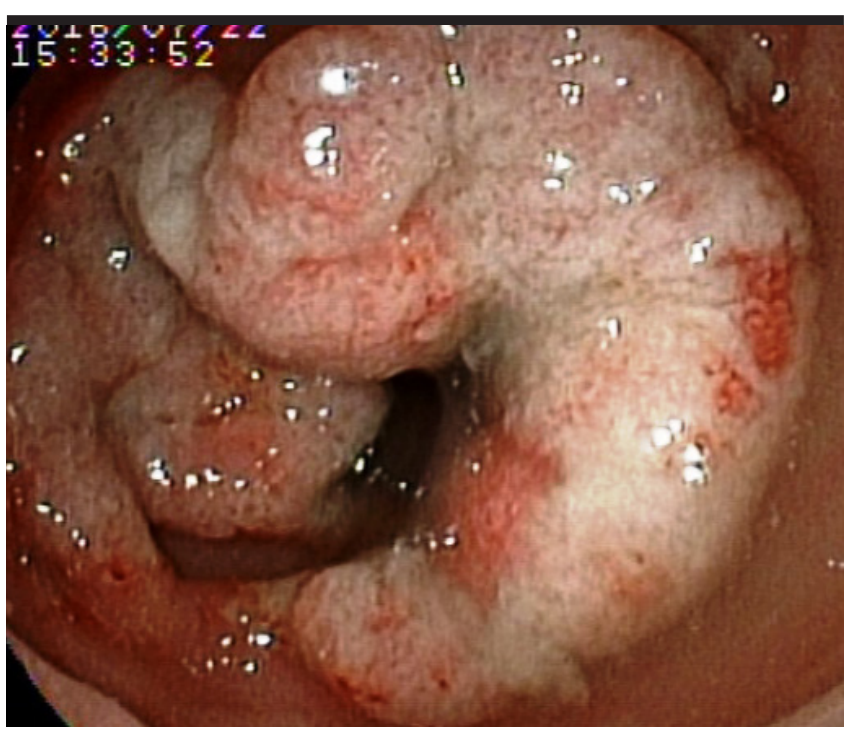

Figure 1. Colonoscopy showed circular tumor-like lesions in the distal rectum

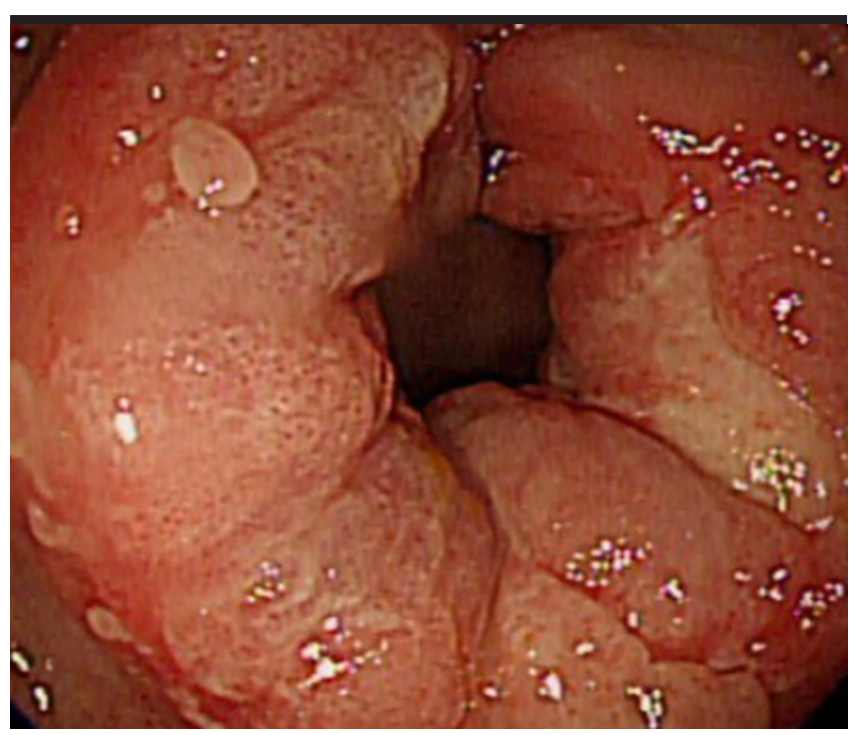

Figure 2. The tumor-like lesions were resected by endoscopic mucosal resection

Corresponding Author: Jen-Wei Chou; codecol@yahoo.com.tw Received: January 6, 2019 Accepted: January 28, 2019

(C) Copyright 2019 by The Turkish Society of Gastroenterology · Available online at www.turkjgastroenterol.org DOI: $10.5152 /$ tjg.2019.19015 


\section{ANSWER}

Inflammatory cloacogenic polyp mimicking rectal cancer Histopathological examination of the rectal tumor-like lesions showed elongated, irregular crypts; surface erosion with exudate coating; abundant neutrophil infiltration; and capillary proliferation in lamina propria (Figure 3 , hematoxylin-eosin stain, magnification $\times 40$ ). Furthermore, hyperplasia of the fibromuscular stroma and up-

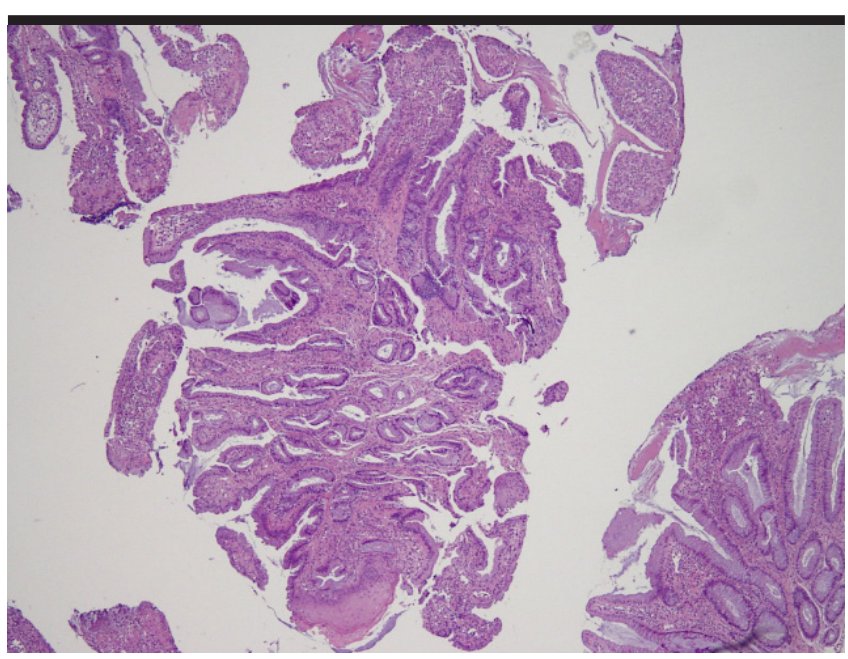

Figure 3. Histopathology of the rectal tumor-like lesions demonstrated elongated, irregular crypts, surface erosion with exudate coating, abundant neutrophils infiltration and proliferation of capillaries in lamina propria (hematoxylin-eosin stain, magnification $\times 40$ )

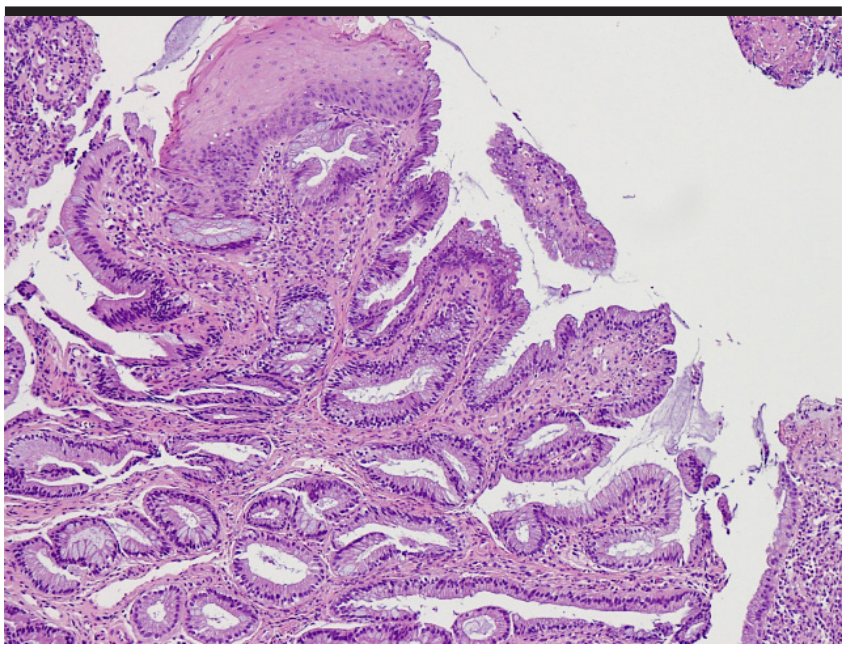

Figure 4. Histopathology showed fibromuscular stroma with smooth muscle upward extension in the lamina propria (hematoxylin-eosin stain, magnification $\times 100$ ) ward extension of smooth muscle in the lamina propria were identified (Figure 4, hematoxylin-eosin stain, magnification $\times 100$ ). On the basis of histopathological characteristics, a diagnosis of inflammatory cloacogenic polyp was made.

Inflammatory cloacogenic polyp is a rare disease arising from the anal transitional zone and lower rectum. The etiology of inflammatory cloacogenic polyp is believed to be related to chronic mucosal prolapse (1). The clinical course of inflammatory cloacogenic polyp is usually benign, and its clinical manifestations include rectal bleeding, tenesmus, and abdominal pain. Endoscopically, inflammatory cloacogenic polyp may present as polypoid growths at the anorectal junction and resembles an anorectal malignancy (2). These lesions are best visualized using a retroflexed maneuver in the rectum on colonoscopy. The diagnosis of inflammatory cloacogenic polyp depends on histopathological findings. Surgical resection is the mainstay therapy for inflammatory cloacogenic polyp (3). However, endoscopic polypectomy or endoscopic mucosal resection is another alternative. Moreover, a high-fiber diet and avoidance of prolonged straining are important for patients with this condition to reduce mucosal prolapse.

Peer-review: Externally peer-reviewed.

Author Contributions: Concept - H.H.C.; Design - H.H.C.; Supervision - H.H.C.; Resources - H.H.C.; Materials - T.W.C.; Data Collection and/or Processing - T.W.C.; Analysis and/or Interpretation - J.W.C.; Literature Search - J.W.C.; Writing Manuscript J.W.C.; Critical Review - J.W.C.

Conflict of Interest: The authors have no conflict of interest to declare.

Financial Disclosure: The authors declared that this study has received no financial support.

\section{REFERENCES}

1. Du Boulay CE, Fairbrother J, Issacson PG. Mucosal prolapse syndrome - a unifying concept for solitary ulcer syndrome and related disorders. J Clin Pathol 1983; 36: 1264-8. [CrossRef]

2. Mathialagan R, Turner MJ, Gorard DA. Inflammatory cloacogenic polyp mimicking anorectal malignancy. Eur J Gastroenterol Hepatol 2000; 12: 247-50. [CrossRef]

3. Tendler DA, Aboudola S, Zacks JF, et al. Prolapsing mucosal polyps: an unrecognized form of colonic polyps a clinic pathological study in 15 cases. Am J Gastroenterol 2002; 97: 370-6. [CrossRef] 